\title{
Appreciative Inquiry for Stress Management
}

Dr Jermaine M Ravalier ${ }^{1}$, Dr Andrew McVicar ${ }^{2}$, and Prof. Carol Munn-Giddings ${ }^{3}$

${ }^{1}$ Bath Spa University, School of Society, Enterprise and Environment

${ }^{2}$ Anglia Ruskin University, Faculty of Health, Social Care and Education

${ }^{3}$ Anglia Ruskin University, Faculty of Health, Social Care and Education

${ }^{*}$ Requests for reprints should be addressed to Dr Jermaine M Ravalier, Bath Spa University, School of Society, Enterprise and Environment, Newton St Loe, Bath, BA29BN , United Kingdom (e-mail: j.ravalier@bathspa.ac.uk).

Key words

Workplace stress

Primary intervention

Daily hassles

Appreciative Inquiry 
Qualitative Research in Organizations and Management

emerald

PUBLISHING

Qualitative Research in Organizations and Management

Appreciative Inquiry for Stress Management

\begin{tabular}{|r|l|}
\hline Journal: & Qualitative Research in Organizations and Management \\
\hline Manuscript ID & QROM-05-2017-1525.R2 \\
\hline Manuscript Type: & Original Article \\
\hline Keywords: & workplace stress, primary intervention, daily hassles, appreciative inquiry \\
\hline \multicolumn{2}{|c}{} \\
\hline
\end{tabular}

SCHOLARONE ${ }^{m}$

Manuscripts

http://mc.manuscriptcentral.com/qrom 
Purpose- Our paper demonstrates the innovative application of an Appreciative Inquiry (AI) approach for the design and implementation of organizational stress management interventions, alongside a case study of the successful design and implementation of the approach. By utilizing the Al methodology to develop a 'local stress theory' for the participating organization, we propose a model which can be utilized in other similar organizations.

Methods- Stage 1: 35 participants completed up to 10 daily logs by answering four positively-framed questions regarding their working day.

Stage 2: semi-structured interviews $(n=13)$. The interview schedule was designed to further elaborate log findings, and begin looking into feasible organizational changes for improvement of stress.

Stage 3: two focus groups (total 13 employees) verified interventions from logs and interviews and discussed how these can be implemented.

Findings- The log stage identified two key themes for improvement: managerial/organizational support and communication. From these, interviews and focus groups led to workable proposals for simple but likely effective changes. We reported findings to management, emphasizing organizational change implementation, and these were subsequently implemented.

Implications \& Limitations- The study demonstrated the effectiveness of Al to identify and implement relatively simple but meaningful changes. The Al cycle was completed but allocating proof-lengthy follow-up time for evaluation of outcomes was not possible, although initial responses were favorable. There are also issues of generalizability of the findings.

Originality- This is among the first studies to utilize an Al approach for the design of stress management interventions.

\section{Key words:}

Workplace stress; Primary intervention; Daily hassles; Appreciative Inquiry 


\section{Appreciative Inquiry for the design of organizational stress management interventions}

There is compelling evidence to suggest that chronic workplace stress has adverse emotional and physiological implications for employees. For example, there are strong links between stress, burnout and depression (Chen et al. 2009; Melchior et al. 2007), and between stress and cardiovascular disease (Rosengren et al., 2004; Yusuf et al., 2004). However, addressing stress in the workplace continues to present a major challenge to employers. For example, in 2015-16 the Chartered Institute of Personnel Development (CIPD, 2016) described stress as being responsible for approximately 11.7 million working days lost in the United Kingdom (UK) alone, and it is the largest cause of long-term sickness absence (i.e. that which lasts 4 weeks or greater) and second only to colds and flu in short term absence in the UK. As an innovative response to this situation, this paper presents the application of Appreciative Inquiry (AI) methodology for the design and implementation of a series of stress management interventions for one public sector organization in the UK.

There is a considerable literature on workplace antecedents for high job stress. For example see the recent review by McVicar (2016) concerning stress in nursing. It is a multi-dimensional phenomenon that has been suggested to require multilevel interventions by combining both individual (secondary intervention) and organisational (primary intervention) strategies (Jones and Johnston 2000). These might include stress education, management strategies, and assistive interventions likely to be policy-related and management-led in order to ameliorate the issues of job demands (e.g. overload, skill mix), management/leadership issues (e.g. support), and personal factors. In the UK a 'standards' approach to eliminating sources of stress is recommended, such as that by the UK Health and Safety Executive (see www.hse.gov.uk/stress/index.htm, accessed $3^{\text {rd }}$ May 2018).

One of the most widely acknowledged models that has influenced thinking on stress within the workplace is the job demands-control model (JDC) (Karasek, 1979), later JDCS following incorporation of social support aspects. The model asserts that employees working in jobs with high levels of demands and low control and social support may result in stress-related strain outcomes (Karasek \& Theorell, 1990). The job demands-resource model (JDR) (Bakker et al., 2003a; Bakker \& Demerouti, 2007) was subsequently developed from the JDCS and places workplace dimensions into a wide range of workplace characteristics in the context of demands being 'buffered' by job resources. The JDR assumes therefore that employees encounter a series of job demands and resources which can either contribute to - or detract from - workplace stress (Minnotte, 2016). 'Job demands' refer to organizational aspects that require physical or psychological effort or skills 
including pressure, task variability, and emotional demands, whereas 'job resources' are those aspects such as management and peer support that help the individual to meet work goals, reduce demands, and/or stimulate personal growth and development (Minottee, 2016).

The JDR is a balance model in that it identifies job resources as buffers which, if adequate, reduce the impact of demands on individual wellbeing (Van den Tooren \& De Jonge, 2008). Should demands chronically out-weigh the buffering then the risk of negative stress-related outcomes is increased (Bakker et al., 2003b). The JDR has therefore been explored alongside a number of outcomes such as burnout symptomology (Schaufeli \& Bakker, 2004), sickness absenteeism (Schaufeli, Bakker \& Van Rhenan, 2009), and work engagement (Hakanen, Schaufeli, \& Ahola, 2008), amongst other factors. It is therefore suggested to be a strong predictor of a number of negative and positive work-related outcomes, and so provides a useful reference point to understand features of the workplace, potential impacts on employees, and strategies for intervention. In this respect it has been long recognised that stress management is most likely to be successful for the majority if it comprehensively addresses systemic sources of stress within the work environment and their interactions (Bond, 2004).

Interventions to manage stress at work may be conceived as primary, secondary, or tertiary (Ivancevich et al., 1990). Primary interventions operate at an organizational level, such as job redesign or enhancing social support, and seek to take pre-emptive action to reduce the stress hazard or limit the employee's exposure to it (Ongori \& Agolla, 2008). It is argued that primary interventions are most likely to lead to long-lasting change (Caulfield et al., 2004; Ongori \& Agolla, 2008). However, to achieve the widespread changes required they normally entail complex psychosocial interventions (e.g. Nytro et al., 2000), and have been utilized much less than secondary or tertiary approaches. Secondary interventions are most commonly utilized in organizations. They are individualized, (Giga et al., 2003) and include approaches such as cognitive-behavioral skills training to increase individual coping capacity/resilience, and strategies to improve time management. Thirdly, tertiary interventions are designed for use after an individual's health has been adversely affected by stress and usually involve mental health professionals as part of a rehabilitative strategy. There is supportive evidence from randomized controlled trials (Seymour \& Grove, 2005) of the efficacy of cognitive behavioral therapy as a basis for secondary and tertiary interventions, but this requires periodic reinforcement as benefits are relatively short-lived when individuals remain in, or return to, an unchanged work environment (Van Wyck \& Pillay-Van Wyck, 2010). 
Primary interventions therefore are preventative and aim to reduce the sources of stress that are the cause of the problem. Such primary-level of intervention is best achieved through culturefocused approaches and participative leadership. Changing a workplace culture is amenable to psychosocial interventions (Caulfield et al. 2004; Hatinen et al. 2007) whereas it is likely to be less amenable to management-led initiatives (authors, 2010, anonymised for review purposes).

Psychosocial interventions require a considerable level of collaborative involvement (Lamontagne et al., 2007). The empowerment of staff to enable their participation is key (e.g. Coffey et al., 2009). Although participative interventions are complex they encourage opportunities for decision-making and recognition of performance, provided that the setting context and unit size have also been taken into account (review, authors 2013, anonymised for review purposes) Such approaches have the potential to facilitate stress reduction and so reinforce professional and organisational commitment (Riahi 2011).

One of the challenges of primary stress interventions is the achievement of a level of employees' participation sufficient to promote widespread change in the workplace. Participatory action research (PAR) is promoted as an effective vehicle for the design of interventions (e.g. Lamontagne et al., 2007; Mikkelsen \& Gundersen, 2003), but it can also be a time-consuming process for participants if they are highly involved in the change process. Alternative approaches that require a lower time-burden are therefore attractive in introducing primary interventions. This study presents the innovative application of an Al methodology towards addressing the frustrations that arise for employees from day-to-day operationalization of existing systems within one public sector organization. As such, we demonstrate a study in which an Al methodology was used in order to develop a model of everyday stress within this organization, followed by the design and implementation of a series of stress management interventions. It has long been considered that significant gains can be made by dealing with such 'daily hassles' that contribute to the erosion of individual well-being (DeLongis et al., 1982).

$\mathrm{Al}$ is a positive change method typology. Its philosophy incorporates a process for engaging individuals from any or all levels of a social organization to produce systematic, effective, and positive change, and has been applied throughout the world in small and large-scale initiatives (Cooperrider et al., 2008). Al is said to have been built on the 'positive psychology' of Seligman of the late 1990s (Billings \& Kowalski, 2008), which promotes the positive aspects of subjective experience 
and individual traits in order to improve quality of life (Seligman \& Csikzentmihalyi, 2000). Al is an approach to both research and action which emphasizes what is working well within an organization, with these positive working practices being further applied to wider elements of the organization. As such the focus is on the positive, in what works well, rather than attempting to identify and 'fix' poor practice (Dewar, 2010). It is therefore based on the premise that every organization has elements which work well, and that these strengths can be the driver for positive change (Cooperrider et al., 2008). Cooperrider and Srivastva's (1987) seminal work developed the Al techniques, which focus on what works well in organizations and other social environments. Therefore, instead of focusing on problems (i.e. a deficit model), Al builds on what works well to build upon the strengths of people or situations (Steyne, 2009) and so transforming the way in which organizational improvement is approached (Cooperrider et al., 2008). It is a participatory approach which aims to demonstrate the shared beliefs and values of individuals within an organization to develop a shared image for change which is positive and meaningful (Atkin \& Lawson, 2006).

Application of Al within an organization is based on the simple assumption that every organization consists of many elements that work well and provide strengths that can be the starting point for creating positive change where deficits exist (Cooperrider et al., 2008). As such, via the use of positivity in questioning and dissemination of data, positive interventions for change can be developed. Al has been successfully applied as a versatile change process across the public sector and is claimed to have numerous applications such as coaching and mentoring, positive culture change, and service delivery in education, health, and the social services (Maclean, 2007; McAllister \& Luckcock, 2009). To the authors' knowledge, however, Al has not been utilized for stress management purposes.

The aim of this paper is therefore to explore the aforementioned Al process within a single, large public sector organization in the South East of England. We present the Al methodology used in order to develop a bespoke 'local' stress theory for this organization, as well as interventions designed and implemented into the organization.

\section{Methods}

This qualitative study took place during 2012/2013 within a large borough council organization in the East of England, UK. As of the end of 2011 the organization as a whole employed 1,045 individuals. The study was situated within one department of this organization that was customer-facing and so 
directly engaged with delivering services. The department employed 188 individuals, divided across a number of working sites over two towns. In particular the organization consisted of one large administrative 'hub' building which supplemented a number of smaller 'satellite' sites. The study took place over a period of 6 months, with each of the stages (see below) lasting one month, with one month between stages. Once interventions for the improvement of everyday stressors were designed within this department, the interventions were implemented across the whole of the organization.

At the time of the study the organization was operating under severe budget constraints imposed by the UK government. It had recently introduced flexible working but, despite this being generally appreciated by employees, stress-related absenteeism was higher than average for the sector (personal communication to Author 1 from senior management; author name removed for blind review). Application of the Maslach Burnout Inventory scale prior to commencement of this study (Authors, 2013) identified a staff base that appeared to be undergoing transition to higher levels of 'exhaustion' and 'cynicism'.

\section{Recruitment}

Two pre-meetings were held during late 2012 and early 2013 to introduce the research team to organizational staff and to discuss the proposed study. These meetings proved key to progressing the study as the council was about to embark on a major reorganization in response to imposed financial constraints, which had exacerbated tension amongst employees. The meetings reinforced that the team were 'outsiders' to the organization (Hurley, van Eyk, \& Baum, 2002) and had approached the council independently with a proposal for the study.

In order to recruit participants, all employees within the participating department were invited to take part in each of the stages of the project, starting with either email or letter to their home if email addresses were not available in Stage 1. It is, however, impossible to determine which participants took part in which stage of the study due to the anonymity of the process. Invitations to participate were disseminated by the Human Resources department and included a stamped addressed envelope for return to Author 1 in order to ensure that management were unaware of the identity of individuals who had volunteered to participate. No financial incentive was made to participants, although it was made clear that they would be contributing to the development of the department and eventually, wider organization. 
Approval for the study was gained from the [university name removed for anonymity] research ethics committee, and access to the organization was granted by its senior management who also identified that Appreciative Inquiry underpinned the organization's approach to customer service evaluation and so its principles were familiar to employees. All analysis was conducted initially by [initials of Author 1] and member checked by [initials of Authors 2 and 3].

\section{Procedure}

The basic initial premise of the Appreciative Inquiry (AI) process applied here within a work environment context is to firstly identify examples of operational process or employee/employer activities that are deemed to work well in the work-place. The intention is to introduce positive viewpoints with the aim of seeking indicators as to how more negative elements might be addressed. This is followed by a request for examples of workplace practices that are less effective or even deemed to be ineffective. The Al process then develops from these identifications in an iterative way with the aim of seeking change to address the negative elements that had been identified. The stages are described in more detail below.

\section{Al Stage 1: Discover}

The task during this first stage of the Al process is to discover the positive exceptions, successes, and most vital or alive moments (see Figure 1 for the Al steps taken in this project). This can be done both within and across organizations (i.e. as a benchmark setting) and across time (for example looking into the history of the organization to discover success stories; Cooperrider, Whitney \& Stavros, 2008). Individuals explain their personal experience of a phenomenon, allowing a researcher to attempt to uncover and strengthen the positive in the phenomenon/situation (Steyn, 2009). Daily logs were therefore chosen for this stage because they allow the description of daily successes, repeated mentions of which could then be taken forward into subsequent stages of the research. Completion of the logs gave individuals from all areas of the social organization the chance to engage in an initiative designed to create systematic and positive change. The logs were used as the source of information by which the need for change is identified, as well as successes which demonstrate how this change can be implemented.

\section{FIGURE 1 ABOUT HERE}

Daily logs are flexible and allow the collection of qualitative data at any particular times of the day, thus making them useful for the capture of short-term experiences of employees (Ohly et al., 2010). 
To minimize the time input required to complete the logs, participants were asked to answer just four questions at the end of each work day. The timing of data collection also was intended to ensure that responses were not based purely on emotion by answering immediately following a specific event during the day. Initial questions were positively framed, in keeping with the inherent philosophy of Al: What went well in your day? Why did it go well for you? Subsequent questions were intended to identify important day-to-day issues for staff, and so inform later discussions as to how utilization of the positive aspects might be applied to ameliorate those issues: What didn't go so well? How could this be improved to make your day more hassle and stress-free?

Thirty-five participants were asked to complete the logs over a two-week period (i.e. 10 successive working days). All participants returned logs but some were incomplete and a total of 152 days' worth of information (out of a possible maximum 350; 43\%) was provided. Responses were analyzed using a 'direct content analysis' (DCA) approach (Hsieh and Shannon, 2005) due to the lack of contextual data and hence the inability to gain the required 'closeness' to the data required for other qualitative data analysis techniques (Braun \& Clarke, 2006). Content analysis is often used in health and wellbeing-related research because it is a flexible data analysis approach, with DCA particularly pertinent here because of the existence of pre-conceived stress, and stress management, theories which thus allows the researcher to conceptualize stress within the organization while being flexible enough to expand upon these conceptualizations (Hsieh and Shannon, 2005).

Following the procedure described by Hsieh and Shannon (2005), AUTHOR 1 first began by familiarization with the data by reading and re-reading each transcript. Following this AUTHOR 1 began identifying initial codes as key demands and resources (as per the JDR) associated with working in the organization, with these initial codes combined into larger categories depending on the number of times the codes were mentioned, and operational titles and definitions provided for these categories. In total three major categories were developed, with divergent categories receiving many fewer mentions and thus not included in the final write-up. AUTHOR 2 also checked the final categories against the initial codes gathered, with any initial category disagreements discussed until consensus developed. To ensure anonymity of response, participants were asked to provide pseudonyms which were based on the nickname of their best friend from childhood.

\section{Al Stage 2: Dream}

This stage involves the creation of a new vision of the future. The assumption is that the research participants naturally begin to search further and envision new possibilities. This envisioning process 
involves creating a positive image of a desired and preferred future (Cooperrider, Whitney \& Stavros, 2008). Within our study, this second stage consisted of a number of semi-structured interviews with staff members. Semi-structured interviews are generally conducted with fairly 'open' frameworks of inquiry which allow for focused, two-way communications based broadly around particular interview schedules (Banister et al., 2011). However, not all questions are designed ahead of time, meaning that the interviewer can question more deeply on interesting themes and concepts which arise, and thus allowing both the interviewer and interviewee to investigate in more depth these topics, or discuss them in greater detail (Banister et al., 2011).

The interviews $(n=13)$ were used to validate operational aspects that were working well, but also provided the opportunity for individuals to expand upon how other operational aspects might be improved by applying similar principles. Semi-structured interviewing therefore allows individuals to put forward their own take on reality, with this process also continuing to stimulate further enthusiasm for change. Also, the interviews allowed participants to 'imagine' the changes that they believe can make a positive impact in the working environment, allowing them to 'Dream' of a positive future.

Participants were recruited from individuals who had expressed interest in the logs from stage 1. Eleven interviews were conducted face-to-face in a room situated away from main work areas in order to ensure confidentiality. The remaining two interviews were conducted over the telephone, with the average interview length 32.5 minutes. All interviews were audiotaped using two digital recorders to ensure clarity and prevent loss of data. Audiotaped interviews from Stage 2 were listened to at least twice to ensure that context and meaning were clear.

The interview schedule was designed initially on the outcomes of the logs while still allowing participants the opportunity to provide their own suggestions. Therefore, each interview began with ethics discussions which highlighted the nature of the study as well as anonymity and confidentiality of answer. Participants were then questioned about positive working practices in their jobs, areas which require improvement, and how this improvement could be made irrespective of the log findings. It was decided that these questions would be asked prior to asking about answers from the log stage in order to prevent bias of answering. Following these questions, the outcomes from the logs were asked of participants, with an emphasis on intervention - in particular how improvements for everyday stressors could be feasibly implemented into the organization. As such, due to the semi-structured nature of the interviews, participants were allowed to diverge away from the 
responses from the logs and develop new ways of working, but for the majority the outcomes of the logs did inform both questioning and answer. Interviews were transcribed verbatim and analyzed via Thematic Analysis (TA; Braun \& Clarke, 2006);

TA is a method for identifying, analyzing and grouping themes or patterns which emerge from data. We utilized an inductive approach to TA, in which the themes identified emerge from the data and reflects the researcher's theoretical underpinning to the project. As such, the coding undertaken was focused upon searching for areas of positive working and how these positive exceptions could be taken into other areas of the organization (Braun and Clarke, 2006). In order to conduct the analysis, verbatim transcripts were initially repeatedly re-read in order to gain familiarity with the data and begin generating initial codes. These codes were grouped into themes, which were reviewed across all transcripts. Themes were chosen due to the 'keyness' of the theme rather than prevalence of that theme because they were important with respect to the aims of the research (Braun and Clarke, 2006). At this point, themes and exemplifying quotations were validated in consultation with Authors 2 and 3. NVIVO 10 qualitative software was used in order to aid in the management of the data collected.

\section{Al Stage 3: Design}

This stage of the Al process describes what 'should be' (Steyn, 2009) and translates what was 'dreamt' in the previous stage into some specific work design on how a service could be improved (McAllister \& Luckcock, 2009). Focus groups were held that allowed participants to design the 'innovative service', i.e. to voice their own narrative upon changes which had been suggested in the previous interview stage while still allowing participants to elaborate on their own designs for interventions.

Data from stages 1 and 2 therefore were taken forward into two focus group interviews. Recruitment of participants was via circulation of an invitation on the intranet. Two focus groups totaling 13 individuals were delivered, one on the main organizational site and one on a large satellite. Each focus group lasted approximately 90 minutes, with the group interview schedule derived from, but not limited to, the results of the semi-structured interviews in Stage 2. In this way it was possible to finalize the participants' proposals for interventions but if new proposals for intervention were brought forward then these would also be discussed. Two of the research team attended and participants were encouraged to identify 'group rules' for the interview, most notably acknowledgement of confidentiality, a recognition that all views put forward were of value and so 


\section{Al Stage 4: Destiny}

Once the shared image of proposed organizational change is gathered, participants are asked to design ways to help move the organization closer to the ideal, and because these ideals are grounded in reality, the organization is empowered to make things happen (Cooperrider, Whitney \& Stavros, 2008). Participatory approaches for change within an organization are most likely to be successful if management is engaged early in the process, and kept informed of developments (Authors 2 and 3; anonymized for review). For this study senior managers of the Directorate that provided the study setting were informed from the start. Members of the Human Resources department likewise were involved in early discussions, particularly individuals involved with the council's stress support strategy and occupational well-being. Departmental managers also contributed to discussions related to the developing Al outcomes as necessary. That process was especially important in Stage 4 since to achieve change the proposals clearly had to be 'championed' and approved. This stage therefore is about committing individuals from across the organization to achieve what was designed in the previous stage so that any changes integrated into the organization are realistic (Akdere, 2005).

In designing this study discussion with management had made clear that significant revisions to organizational systems, especially where technology would require considerable investment, would not be feasible. This was not problematic as the initial proposal for the study was more related to operational issues within the systems. The rationale was that relatively small changes to make 
significant differences to the daily work of employees were most likely to be amenable to revision and acceptable to management.

Lunt et al., 2007 identified that improved stress outcomes following organizational change are more likely to be lasting if they engender a positive attitude to collaborative learning among managers and workers. Large scale change clearly requires commitment by organization leaders to any suggestions put forward for implementation. Not surprisingly it is helpful if managers recognize the value of an intervention and that it is only the start of a continuing process of improvement (Halbesleben et al. 2006). Nevertheless fully engaging management can be difficult (Authors 2 and 3, anonymized for review) and for the present study we had an advantage firstly because the Council had made the initial contact with authors $\mathbf{2}$ and $\mathbf{3}$ to discuss workplace attrition. Secondly, in proposing a 'daily hassle' approach it was more open to working directly with middle managers, rather than senior management, to facilitate any revisions to work practice.

Within our study, we ensured that the shared vision for the future which was created during the process was fed-back to department managers and brought into one of their regular meetings as a distinct item for discussion that dominated the meeting agenda at that time. Authors 1 and 2 attended the meeting for an open discussion with managers, and Human Resource representatives in the group, to decide upon which proposed changes might be viable across the departments and hence Directorate, and likelihood therefore of implementation. Indeed, we determined the success of the Al process according to whether or not suggested interventions that came out of the process were implemented within the departments.

\section{Results}

\section{Al Stage 1: Discover (Daily Logs)}

Stage 1 of the Al process (Discover) is to discover positive examples of practice within the organization. Content analysis of the daily log data identified two predominant areas that participants considered were 'working well', and three that 'required improvement'. The most prominent area found to be working well related to productivity and professional efficacy as a positive outcome during the working day. As such, participant examples of responses are:

"Was able to clear a number of pieces of work". (Participant Sun)

"Increased productivity, lots of tasks completed". (Participant Cast) 
"Felt that I had achieved a lot. Caught up with talking to some of the team" (Participant Passerby)

The second aspect that was working well was the peer support offered to participants by colleagues. This support was evident in a number of ways from providing emotional support and help, to providing practical support for the completion of large and complex tasks:

"Had a really productive discussions [sic] with colleagues which offered me a lot of peer support". (Participant Cart)

"Good communication with a colleague in the office while I was working at home" Participant Acthinker)

"Every work colleague I've come into contact with today has been really sweet and understanding of the pressure I'm under - they've been supportive and helpful'. (Participant Knac)

It was clear that completing work set and the support from colleagues that contributed to this, were the focus of job satisfaction expressed by participants. The premise of the 'Discover' stage is that it provides some insight into significant positive aspects of the workplace, with a view to transferring their potential to areas of work that were not considered to be as effective or satisfying. (see Procedure, earlier). In this respect connections were not immediately obvious. Thus, prominent areas found to be in need of improvement included the quantitative workload/demands faced by respondents and so appeared to be incongruent with the positivity of staff as to their professional efficacy. However it was differentiated by reference to processes that potentially prevented job completion. Firstly, by having more structured and clear-cut workloads handed down:

"Too many areas of work that require the same level of attention and priority, making it difficult to structure the day." (Participant Cast)

"Finding that I was having to take on additional workload." (Participant Huff)

Secondly, by the number of emails that they received on a daily basis:

"Had to ignore emails and phone messages to get this done. More work coming in than going out, more phone messages and email than have time to answer, know it's only going to get worse for the next month or so." (Participant Minerva)

Thirdly, top-down communication, which was described as 'dominant' in the organization, did not allow employees to put forward their own suggestions for workplace improvement: 
"Very poor communication from management team surrounding a significant incident at work last week. A good example of poor communication - colleagues were left feeling locked out and disenfranchised by management team response." (Participant Cart)

The outcomes of Stage 1 therefore highlighted the importance of professional efficacy and the peer support required in order to achieve that as positive features of their workplace, but also identified constraints related to organizational/managerial and/or communication issues. These latter points therefore provided initial insight not only into the workload issue per se but factors that were contributory to not meeting those workload commitments. In relation to the positive aspects, the data indicated that negativity arose from having to prioritise work received perhaps unnecessarily at the same level, introduction of time pressures by an overwhelming use of email by senior colleagues, and poor communication between managers and staff were hindrances to achieving staff goals. These viewpoints were taken forward to be explored in more detail in Stages 2 and 3.

\section{Stages 2 and 3: Dream and Design (Interviews and Focus Groups)}

Thematic analysis of data from individual interviews (Stage 2) and focus groups (Stage 3) confirmed and extended the issues identified in Stage 1. Participants in the focus groups who had not taken part in Stages 1 and 2 agreed strongly with the themes and suggestions that had been put forward, although further suggestions were also proposed by the focus groups. Findings from these stages are considered below in relation to the research themes and outcomes that emerged from Stage 1, though in some instances the issues were inter-related as arising from shortfalls in organizational communication strategies.

\section{a) Theme 1: Organizational/managerial support}

Participants built upon comments made in Stage 1 by describing a lack of support from peers as well as communication between managers and staff, and between colleagues based in different sites, as sources of stress. As noted earlier, the organization comprised a hub and satellite sites, and one of the issues described by satellite employees was a perceived lack of managerial support away from this main hub. Additionally, the geographical distance between the hub and satellite sites caused individuals to feel excluded from many of the main corporate events that usually are held at the main site:

"The [name of service] either in [name of place] feel a little bit distant from the rest of the organization because, well I suppose they're separate sites and especially [name of site] are so far away." (Interviewee 12) 
"...you're working in one town and you never go into another town, the other part of the organization will always remain a bit of a mystery". (Interviewee 8)

Focus group participants suggested that a lack of a physical presence by management was the key issue here, and that there appeared to be no reason as to why organizational functions could not at times be held outside of the main site in order to promote a feeling of integration with the rest of the organization.

Secondly, lack of perceived contact with managers prompted additional discussion, beyond the issues raised in Stage 1, concerning what was considered a distinct lack of organizational support for individuals who felt that they had experienced workplace stress to a level which became disturbing, even though there is a legal requirement for organizations to help staff to reasonably deal with workplace stress (Health and Safety at Work Act, 1974). Peer support, identified in Stage 1 as a positive aspect of the workplace, was also clearly an important resource for colleagues who felt over-stressed. However, respondents being aware that organizational systems and procedures were in place did not know which options were available should they feel they were becoming negatively affected by stress. Consequently, at times they felt alone despite support from colleagues (who they did not wish to overburden):

"But yeah it literally was that, I didn't know who to talk to, who to turn to, and I couldn't face complaining to any more colleagues because they knew that I was upset." (Interviewee 4) "I did get really stressed out recently erm, I didn't know particularly what to do". (Interviewee 5)

The scale of this issue was identified by some participants who described that working within the organization at times became too much for them. For example:

"There have been a couple of times when... when I've just had to kind of leave the office and lock myself in a cubicle somewhere to give myself a couple of minutes to wipe away the tears and compose myself" (Interviewee 4)

Building on one of the themes from Stage 1 and 2 the focus groups suggested that the organization should take steps to improve practical support in areas of work by developing and enabling peer support, whilst ensuring that this did not become an imposition for the individuals involved. For example, there was reflection upon the problems some staff faced when new IT technology or services were introduced, which was quite frequent. It was identified that some colleagues had much better IT abilities than others, and so the organization might find the means to harness that 
expertise in order to help those who may struggle with IT, though without compromising their work responsibilities. For example:

"When we did introduce like the VOIP telephony system I think... what should have happened is those individuals should be trained up to a level of understanding and those individuals then would've had the time and skills to be able to spend time with other people around the organization and demonstrate to them how the application works". (Interviewee 3)

Recognition by the organization of the potential for creativity within employees' roles was also put forward as a potentially-important step forward. Where individuals were able to design and carry out new projects and procedures then respondents had found this to be a very positive experience:

"At the beginning of the year I put forward two pages of ideas and events that either I could do or other people could do and not one of them has been taken up". (Interviewee 10) However, opportunities to be innovative were scant and even when proposals were put forward they were rarely followed up:

"what you have got to understand is we have got the most amazing talented people and they're degree-level educated, erm they're creative you know they're writers they're artists, everything that you need to do in [name of service] could be done through the pool of staff that we've got you know? And I say what about if we do it this way, but then they'll go and spend 1600 on somebody from the outside to come in." (Interviewee 9)

Focus groups supported these comments with further illustrations of what were considered to be middle management 'blocks' to suggestions for change to procedures, and emphasized a lack of feedback. Group participants expressed wanting a 'voice' within the organization, in which they could, anonymously or not, put forward their own suggestions as to how the organization could be improved. A lack of an appropriate forum to communicate ideas to senior management was apparent, as also was evidence that any communicated suggestions were given serious consideration. Participants in interviews had discussed the use of a suggestion box within communal areas which could be used to provide constructive suggestions for improvement of both the running of the organization as well as the working environment. However, they were skeptical of management interest in the current setting:

"I thought of that too [an anonymous suggestion box] but then it's like would they, would it actually be effective?" (Interviewee 6)

b) Theme 2: Communication constraints 
Concerns regarding poor effectiveness of communications between managers and staff led to expression of an overriding feeling from participants that working at satellite sites left them feeling separated from the rest of the organization and a feeling of isolation, and thus a lack of organizational support:

"You know we could meet our colleagues in [name of place] over the internet just for a oneto-one, I mean obviously occasionally it's good for me and travel for those one-off meetings but if you wanna have a conversation..." (Interviewee 6)

Departmental meetings were held frequently and were considered by respondents, including by satellite staff, as an ideal vehicle for two-way, bottom-up communication. However, participants described the meetings as inappropriate for purpose, being used either as an exercise to criticize staff, or as an opportunity for gossiping:

"We have our regular Tuesday meeting which is the time that stuff has, you know that needs to be said is said, erm and it's become an exercise in bashing people over the head."(Interviewee 9)

"Often they're just a time to eat cake and there'll be discussions about cake, what people are wearing and where they're going on holiday and it's not particularly effective for information sharing."(Interviewee 1)

It was also clear that lateral communication with other departments did not take place. The focus groups highlighted that staff in the department were unaware of possible parallel activities which colleagues could learn from, or perhaps contribute advice.

In view of such comments, the focus groups were asked to describe how management maintained vertical communication. Discussions identified a reliance on using the organizational intranet, which was considered short-sighted since (at that time) many customer-facing staff did not have access to it from outside of their main office. Introduction of flexible working without full access to a satisfactory IT system was a strong issue for some participants as it meant that flexible working from home or when in the community at times became very problematic. Additionally, important personal information such as payslips was also only accessible via the intranet, and so not available to a proportion of staff.

Regarding emailing, Stage 1 had identified this as a significant negative aspect of work. The interviews in Stage 2 reinforced this as a major source of pressure for staff and described two main frustrations: over-reliance on this means of communication, and its improper use. Email was 
described as being used as a replacement for face-to-face communication, with an expectation of immediacy of response. Excessive use of emails added significantly to their workload:

"Stop sending me emails every 5 minutes when you're in the opposite room going 'oh have you done this, have done that, what's going on with this?" (Interviewee 1)

"In terms of email I think in my point of view the biggest problem with an email is if someone emails you they expect an immediate response." (Interviewee 2)

During interview, some participants had suggested that staff be allowed to turn-off their 'email client' during busy periods to enable greater concentration on tasks in hand, but with a proviso that all staff would be encouraged to flag 'Urgent' emails as appropriate in order to identify prioritization of workload.

"Accept periods when Outlook is turned off at the workstation but with periodic checks for urgent messages". (Interviewee 11)

Focus groups agreed with this and also suggested management should consider a policy across the organization of preferentially using verbal communication whenever appropriate. One focus group member commented:

"To me email is less about documenting actually and more about just getting to somebody, and if it's something important I will always pick up the phone." (Participant 12)

Focus group discussions additionally identified difficulties caused when people were absent, since failure to respond was understandably poorly received by customers despite out-of-office messages. This had negative effects on customer relations, service delivery, and also on the individual concerned when they returned to work. It was agreed that peer support could be engaged in this situation by introduction of a 'buddy' system whereby staff on planned absence would themselves negotiate and nominate colleagues to be able to respond to urgent emails in their place.

Stages 1, 2 and 3 completed the evaluative aspects of the Al cycle by identifying day-day issues, and potential means of addressing them, for employees working within current operational parameters in the participating departments. The process was iterative. Stage 1 identified what participants considered key 'hassles' that impacted on their capacity to deliver work, causing stress as a consequence. Individual interviews in Stage 2 reinforced these views and elaborated further with examples. The focus groups in Stage 3 again validated the viewpoints that had been expressed, elaborated yet further. As noted the outcome of these three stages was the recognition of relatively small changes that participants considered would make a significant contribution to reducing 
prominent 'hassles' in their work and, by implication from Stage 1, impacting on their job satisfaction.

This study was located theoretically within the job demands-resources model of Bakker and Demerouti (2007; see Background section) which recognises the importance of a 'balance' between job demands and job resources in preventing excess employee stress. The focus of that model is on various broad dimensions of the work environment in these respects. Demands arising from high workload are therefore very common causes of imbalance but so are deficiencies in some aspects of job resources. Evaluations using models such as the JD-R therefore tend to identify broad but relatively unspecific sources of workplace stress. For example, to first evaluate the departments we had initially conducted a quantitative study just prior to this qualitative one in order to identify the dimensions of stress that could be flagged-up for wider attention (Authors 1,2,3, anonymised for review). This was through a survey comprising the UK Health and Safety Executive's Management Standards Indicator Tool (MSIT; Kerr et al. 2004) combined with the Maslach Burnout Inventory (MBI; Maslach et al. 1986). Priority workplace concerns were identified as demands, management, relationships, role and change suggesting a broad range of issues in the context of burnout risk although regression analysis had identified different predictors for the sub-scales of the MBI. Such findings are of wider interest and of value to managers as a basis for larger scale interventions/developments to improve the work environment but they are of limited value in the context of 'daily hassles'. The benefit of the collaborative approach in evaluating those 'hassles' is that the method makes no assumptions as to specific problems that are operative in the local setting. Using a collaborative Al approach this enabled us to identify specific issues which, though small scale in the grand scheme of an organisational workplace, represented significant 'hassles' for the participants and therefore potential sources of cumulative impact that is characteristic of chronic stress. In other words it identifies a 'local stress theory' for that setting at that time.

Figure 2 presents the 'local stress theory' within the context of the JD-R. The theory was developed as an outcome of the iterative qualitative research processes, reflecting elements in the study which have required improvement and provide potential buffers to cumulative negative outcomes such as Burnout (Authors 1, 2, and 3). It relates to particular stressors, as described by participants, and the way in which they can be buffered by positive organizational practices. At the left of the figure the issues for improvement are located conventionally in the context of broader dimensions, that is, job demands, managerial and organizational support, and communication. One feature of the JD-R as a balance model is that high levels of job resources are considered to help buffer the impact of job 
Figure 2

\section{[Figure 2 near here]}

Having identified the local stress theory the study, and agreed proposals as the means to ameliorate negative issues for staff, the findings from Stages 1-3 set the stage for proposals to be taken forward to managers for implementation in Stage 4.

\section{Stage 4: Destiny (Interventions)}

The local stress theory, and subsequent proposals for change, were presented to middle management within the organization at one of their regular meetings. These included representatives from the Human Resources department. The outcomes from Stage 3 had been sent to them for prior discussions and Authors 1 and 2 attended the management meeting to address requests for clarification and issues regarding the proposals, but also represented the participants' views. Discussions prompted a number of subsequent interventions designed to extend and improve the capacity for peer involvement in day-to-day operations, and to improve the degree of communication and integration between managers and staff. Indeed, during the 'Discover' stage this communication with management was a clearly determined finding. Suggestions therefore especially centered on ensuring that employees had a voice, and that this voice would be listened to: 
- Managers with specific responsibilities for staff on the satellite sites would be required to spend a greater proportion of their time at the sites. They would also be expected to be highly visible and to link more closely with individuals. Corporate events would be scheduled at satellite and hub sites.

- The organization's Human Resources department would print hard copies of the organization's wellbeing strategy and distribute them to all staff communal areas. Wellbeing representatives already present in the hub site would also be appointed at the satellite sites to help reduce perceived isolation, and a perceived lack of support for stress management.

- Suggestion boxes in communal areas would be trialed, in which employees could provide constructive developmental suggestions to management. Management agreed to respond directly to as many of these suggestions as possible, and would place the suggestion and their response on the intranet.

- Departmental meetings would be made more transparent, with minutes and actions for all team meetings placed on the organizational intranet for all to see. Arrangements would be made for department representatives to attend meetings of other departments on occasion, for feedback and improved lateral communication.

- Employees would be enabled to access important information regarding their employment from home as well as work. Steps would be taken to ensure that the intranet system was rolled-out more widely to ensure it was fully available to all staff from outside the workplace.

Managers were at the time resistant to the suggested introduction of a 'buddy' email system to cover staff absence in view that it potentially could increase demands, and hence have a negative effect on the 'buddy', but they did agree that this should be reviewed in the future. However, they were antagonistic to suggestions regarding a more frequent use of face-face/telephone conversations rather than emailing, and also permission to turn off emails at busy periods. Despite identification of email usage as a major barrier to professional efficacy, and the willingness of staff to prioritize as necessary, the risk of a potentially problematic break in communication between management and staff, especially when staff were working from home and so not accessible on work premises, was deemed too high for organizational efficiency. This was a disappointing outcome.

\section{Discussion}


The aim of this study was to explore and demonstrate the utility of an Al approach for the design and implementation of interventions aimed at improvement of everyday stressors in the workplace. By adopting an $\mathrm{Al}$ approach this paper presents a series of interventions for the management of these everyday stressors, with the interventions designed and subsequently implemented by management in one public sector organization in the UK. As such by presenting these outcomes we demonstrate the utility of the methodology in this context, as well as a local stress theoretical approach which can subsequently be utilized by similar organizations in the management and design of work stress interventions.

The interventions designed and subsequently adopted into the organization related to what could appear to be relatively small gains, but these were tailored to long-standing frustrations and difficulties identified by employees themselves. This study therefore was successful in securing operational change for employees by addressing daily operational 'hassles' using the Al process. The exception was the refusal of managers to relinquish predominant communication links via email, despite employees' willingness to adopt a priority system. Some systemic issues clearly may require much higher-level strategic thinking of management who facilitated this study but did not participate in it.

Primary interventions are tailored to issues sensitive to the specific workplace situation rather than to pre-formed assumptions, and so are likely to secure change (e.g. Lamontagne, et al., 2007; Ongori \& Agolla, 2008). Appreciative Inquiry as applied in this study mirrored some of the recommendations put forward by Author 2 et al. (2013) in terms of engagement and scale, i.e. that the participating organizational unit should not be too large (100 employees or so), and the study aims not overambitious (hence the focus on daily hassles). The enthusiasm of a Head of Directorate, the head of the participating department, and a head of another department in the Directorate, were critical in enabling access by an 'outsider' research team to the sites, to organizational data on absenteeism and stress management policies, and to employees, so acting as internal 'champions' whose input facilitated and encouraged participation. The familiarity of employees with the application of an Al approach to customer service quality assurance processes also appeared to overcome signs of early resistance from staff but employees required further reassurances that their time-involvement would be manageable, that the research team were independent of any organizational agenda other than looking to help reduce stress-related absenteeism, that management would act only in a facilitation role, and that staff would be kept informed of study progress and outcomes. 
The Al process is iterative and inductive. Collation of the outcomes from the logs, interviews and focus groups provided a local 'stress theory' that could be located within the job demands-resources model (JDR; Bakker \& Demerouti, 2007). Figure 2, the local stress theory, illustrates that perceived demand (quantitative workload) could be lessened at the study site by a sense of satisfaction from work completion. However, findings also indicated a deficit in specific resources (organizational/managerial constraints, and communication constraints) that appeared to elevate the pressure related to completing work activities rather than acting as buffers. This may explain why buffering largely came from peer support, which was viewed as a particularly instrumental resource for work completion and also offered emotional support. Participants were keen for the importance of peer support to be recognized, facilitated, and developed. Relatedly, participants also felt strongly that employees were well-placed to suggest bottom-up solutions to operating difficulties, but employee creativity was not actively encouraged by the organization. The positive aspects of Al methodology therefore provided an agreed focus for change that was related to the positive elements of collegiate working and workplace justice as the means to reduce stress arising from operational factors.

\section{Limitations}

In applying Al, a potential limitation common to iterative study is the criticality of findings which emerged from the very first stage of data collection, since this stage establishes the focus for successive stages. In the present study, this stage entailed completion of daily logs (diaries) which have proved effective in studies of occupational stress and well-being (e.g. Jones et al. 2007), but their application in any study ought to be reflected upon in the context of their application. In this study, an important methodological issue for employees considering participating was the possibility of excessive time requirements. To address this the logs were designed to require just a few minutes of participants' time at the end of their day. The possible trade-off is the risk that answers may have been superficial as a consequence of rapid completion. However, validation of the themes that arose from analysis of the logs was supported by the interviews and focus groups, the latter being attended by some employees who had not taken part in Stage 1 but who also agreed strongly with the issues and emergent findings.

A further limitation of this study, in seeking the evidence of efficacy of Al, lies in the lack of follow-up to evaluate sustainability of impact, a commonplace occurrence in many organizational change projects (Richer et al., 2010). The study ended with the confirmed introduction of agreed changes, but the longer-term success and/or impacts of these changes, or how widely they were actually used 
by staff, were not evaluated. The lack of definitive evaluation highlights a deficiency of the Al model proposed by Cooperrider et al. (2008), in that the Al cycle does not take this into account. As such, a recommendation to introduce 'Deliberate' as a 'fifth $D$ ' is suggested by the authors. Follow-up is often problematic for primary interventions as it is in this project. To convincingly demonstrate an improved work environment, and subsequently a lowered absenteeism, study outcomes ought to be followed through for at least 9-12 months (Authors 2 and 3, 2013; anonymized for review).

In this study the interventions were rolled-out to the departments, other than the excessive email issue which management were adamant could not be addressed. Despite this assurance the timing of the project undermined any capacity to evaluate impact of the interventions over several months. The cumulative effect of financial stringency in the UK in recent years took its toll with downsizing and reorganization of the study site. We took the opportunity, with permission, to repeat a survey of the developing effect of such major changes (authors 2014; anonymized for review purposes) and (using the MSIT noted earlier; Kerr et al. 2004) identified exaggeration of the organizational dimensions that were of concern 12 months previously (authors 2013; anonymized for review purposes) and using the MBI (Maslach et al. 1986) found a considerable increase in emotional exhaustion and cynicism, the two key components of burnout. The efficacy of interventions to reduce stress for employees is sensitive to the impacts of any major changes that might occur during such a key time to evaluate study impacts (Haukka et al., 2010) and it seems likely that other 'hassles' would have arisen at the study site.

In order to trial the application of Al, this project utilized the methodology in a single organization in order to create a local stress theory and series of interventions for the improvement of everyday work stressors. Generalizability therefore is an issue in transferability of the local stress theory which may not be applicable to other, similar organizations. Nevertheless, the utility of Al in generating the local stress theory and strategies for simple, meaningful change to alleviate operational sources of stress has been demonstrated for application in similar UK public-sector organizations. This project presents the findings of utilizing an Al methodology in a single organization in order to create a local stress theory and series of interventions for the improvement of everyday work stressors. However, the small sample size and use of a single organization means that generalizability is an issue. Despite this, the predominant aim was to develop a methodological process that leads to a context specific local stress theory with tailored solutions and hence the process could be applicable to other, similar public sector organizations in the UK. From this theory those organizations could seek to develop a series of stress management interventions for every day stressors using an Al approach in similar UK 
public-sector organizations. As such, the Al methodological approach taken in this project can be used in a variety of organizations and a variety of settings.

Finally, this study also suggests directions for further studies. Most importantly, as far as the authors can ascertain, it represents the first reported attempt to utilize an Al approach for stress management. Al appeared to be highly effective in the context of the study setting, but its utility requires evaluation in other settings. Additionally, systematic and empirical investigation is required to identify if the use of an Al approach can more positively affect employee wellbeing in comparison to a more negatively-based discourse.

\section{Conclusions}

This study contributes to primary approaches to stress management through the application of Appreciative Inquiry (AI) methodology to address daily hassles that potentially could impact on staff well-being. It provides an exemplar of the way in which Al can be successfully administered within a large public-sector organization. Key organizational figures enabled the study to take place, but manageable time requirements, an existing awareness of the principles and aims of $\mathrm{Al}$, and affirmation of the independence of the research team also appeared to be instrumental in its progress. In addition to the identification of positive elements of employees' workday, this application of Al methodology also enabled structured, readily-implemented, and low-cost changes to be proposed as the means to address significant operational job resource deficits, leading to their translation into actual interventions by managers. Al methodology appears to be an effective vehicle to identify foci for primary interventions for modest sources of stress in the workplace. 
$\underline{\text { References }}$

Akdere, M. (2005), “Appreciative Inquiry: A field study of community development”, Systemic Practice and Action Research, Vol. 18 No. 1, pp. 21-34

Atkin, H., and Lawson, S. (2006), "Participative service redesign using Appreciative Inquiry", International Journal of Therapy and Rehabilitation, Vol. 13 No. 3, pp. 102

Bakker, A.B. and Demerouti, E. (2007), "The Job Demands-Resources model: State of the art", Journal of Managerial Psychology, Vol. 22, pp. 309-328

Bakker, A.B., Demerouti, E., De Boer, E., and Schaufeli, E.B. (2003a), “Job demands and job resources as predictors of absence duration and frequency", Journal of Vocational Behaviour, Vol. 62, pp. 341356

Bakker, A.B., Demerouti, E., Taris, T.W., Schaufeli, W.B., and Schreurs, P.J. (2003b), “A multigroup analysis of the Job Demands-Resources model in four home care organizations", International Journal of Stress Management, Vol. 10, pp. 16-38

Banister, P., Bunn, G., and Burman, E. (2011), "Qualitative methods in psychology: a research guide" $\left(2^{\text {nd }}\right.$ Ed.), London: McGraw-Hill

Billings, D, and Kowalski, K. (2008), "Appreciative Inquiry”, Journal of Continuing Education in Nursing, Vol. 39 No. 3, pp. 104

Bond F.W. (2004), "Getting the balance right: the need for a comprehensive approach to occupational health". Work and Stress 18,pp146-148

Braun, V., and Clarke, V. (2006), "Using thematic analysis in psychology", Qualitative Research in Psychology, Vol. 3, pp. 77-101

Caulfield, N., Chang, D., Dollard, M.F., and Elshaug, C. (2004), "A review of occupational stress interventions in Australia", International Journal of Stress Management, Vol. 11 No. 2, pp. 149-66

Chartered Institute of Personnel Development (2016), “Absence Management: Annual Survey Report 2014", available at: https://www.cipd.co.uk/Images/absence-management_2016_tcm18-16360.pdf (accessed 20th April 2017)

Chen, W-Q., Siu, O-L., Luz J-F., Cooper, C.L., and Phillips, D.R. (2009), “Work stress and depression: the direct and moderating effects of informal social support and coping", Work \& Stress, Vol. 25 No. 5, pp. 431-443

Coffey M, Dugdill L \& Tattersall A (2009). “Designing a stress management intervention in social services". International Journal of Workplace Health Management 2 (2), pp98-114

Cooperrider, D.L., and Srivastva, S. (1987), “Appreciative Inquiry in organizational life”. In Pasmore W, and Woodman R (Eds.), Research In Organization Change and Development (Vol. 1), Greenwich, CT: JAI Press, pp. 129-169

Cooperrider, D.L., Whitney, D. and Stavros, J.M. (2008), Appreciative Inquiry Handbook: For Leaders of Change, $2^{\text {nd }}$ Ed., Brunswick, $\mathrm{OH}$ : Crown Custom Publishing 
DeLongis, A., Coyne, J.C., Dakof, G., Folkman, S., and Lazarus, R.S. (1982), "Relationship of daily hassles, uplifts, and major life events to health status", Health Psychology, Vol. 1 No. 2, pp. 119-136

Dewar, B. (2010), "Editorial: Appreciative Inquiry", International Journal of Older People Nursing, Vol. 5 No. 4, pp. 290-291

Giga, S.I., Cooper, C.L., and Faragher, B. (2003), "The development of a framework for a comprehensive approach to stress management interventions at work", International Journal of Stress Management, Vol. 10 No. 4, pp. 280-296

Hakanen, J.J., Schaufeli, W.B., and Ahola, K. (2008), "The Job Demands-Resources model: A threeyear crossed-lagged study of burnout, depression, commitment, and work engagement", Work \& Stress, Vol. 22 No. 3, pp. 224-241

Hatinen M, Kinnunen U, Pekkonen M \& Kalimo R (2007) “Comparing two burnout interventions: perceived job control mediates diseases in burnout". International Journal of Stress Management 14(3),pp 227-248

Haukka, E., Pehkonen, I., Leino-Arjas, P., Viikari-Juntura, E., Takala, E.P., Malmivaara, A., and Hopsu, L. et al. (2010), "Effect of a participatory ergonomics intervention on psychosocial factors at work in a randomized controlled trial", Occupational and Environmental Health, Vol. 67 No. 3, pp. 170-177

Health and Safety at Work etc. Act (1974). Available at http://www.legislation.gov.uk/ukpga/1974/37/contents (accessed 20th April 2017)

Hsieh, H-F., and Shannon, S.E. (2005), "Three approaches to qualitative content analysis", Qualitative Health Research, Vol. 15 No. 9, pp. 1277-1288

Hurley, C., van Eyk, H., and Baum, H. (2002), "Insider knowledge and outsider objectivity - the benefits and risks of combined evaluator roles in a study of health care reform", Evaluation Journal of Australasia, Vol. 2 No. 2, pp. 60-68

Ivancevich, J.M., Matteson, M.T., Freedman, S.M., and Phillips, J.S. (1990), “Worksite stress management interventions", American Psychologist, Vol. 45 No. 2, pp. 252-261

Jones MC \& Johnston DW (2000) “Reducing distress in first level and student nurses: a review of the applied stress literature". Journal of Advanced Nursing 32(1) 66-74.

Jones, F., O'Conner, D.B., Conner, M., McMillan, B., and Ferguson, E. (2007), “Impact of daily Mood, work hours, and iso-strain variables on self-reported health behaviours", Journal of Applied Psychology, Vol. 92 No.6, pp. 1731-1740

Karasek, R.A. (1979), “Job Demands, Job Decision Latitude, and Mental Strain: Implications for Job Redesign", Administrative Science Quarterly, Vol. 24, pp. 285-308

Karasek, R.A., \& Theorell, T. (1990), Healthy work: stress, predictivity, and the reconstructin of working life, Basic Books, New York, NY

Kerr R, McHugh M, McCrory M. (2009), "HSE management standards and stress-related work outcomes". Occupational Medicine (Lond) Vol. 59:pp574-579. 
Lamontagne, A.D., Keegel, T., Louie, A.M., and Landsbergis, P.A. (2007), "A systematic review of the job-stress intervention evaluation literature, 1990-2005", International Journal of Environmental Health, Vol. 13, pp. 268-280

Maclean, G.D. (2007), “Appreciative Inquiry: Reducing maternal and neonatal morbidity and mortality", British Journal of Midwifery, Vol. 15 No. 11, pp. 702-706

Maslach C, Jackson SE, Leiter MP, Schaufeli EB, Schwab RL. (1986), "Maslach Burnout Inventory Instruments and Scoring Guides". Mind Garden, Inc. www.mindgarden.com last accessed $3^{\text {rd }}$ May 2018.

McAllister, K., and Luckcock, T. (2009), “Appreciative Inquiry: A fresh approach to continuous improvement in Public Services", House, Care and Support, Vol. 12 No. 1, pp. 30-33

McVicar,A. (2012, "Scoping the common antecedents of job stress and job satisfaction for nurses (2000-2013) using the job demands-resources model of stress". Journal of Nurse Management

\section{Author 2 and others (2013), Detailed withheld for peer review}

Melchior, M., Caspi, A., Milne, B.J., Danase, A., Poulton, R., and Moffitt, T.E. (2007), "Work stress precipitates depression and anxiety in young, working men and women", Psychological Medicine, Vol. 37 No. 8, pp. 1119-1129.

Mikkelsen, A. and Gundersen, M. (2003), "The effect of a participatory organizational intervention on work environment, job stress, and subjective health complaints", International Journal of Stress Management, Vol. 10 No. 2, pp. 91-110

Minnotte, K.L. (2016), “Extending the job demands-resources model: predicting perceived parental success among dual-earners", Journal of Family Issues, Vol. 37 No. 3, pp. 416-440

Nytro, K., Saksvik, P.O., Mikkelsen, A., Bohle, P., and Quinlan, M. (2000), "An appraisal of key factors in the implementation of occupational stress interventions", Work and Stress, Vol. 14 No. 3, pp. 213225

Ohly, S., Sonnentag, S., Niessen, C., and Zapf, D. (2010), "Diary studies in organizational research: An introduction and some practical recommendations", Journal of Personnel Psychology, Vol. 9 No. 2, pp. 79-93

Ongori, H. and Agolla, J.E. (2008), "Occupational stress in organizations and its effects on organizational performance", Journal of Management Research, Vol. 8 No. 3, pp. 123-135

\section{Authors (2013)}


Riahi S (2011). "Role stress amongst nurses at the workplace: concept analysis". Journal of Nursing Management 19, pp721-731.

Richer, M-C., Ritchie, J. and Marchionni, C. (2010), "Appreciative Inquiry in health care”, British Journal of Healthcare Management, 16 (4), pp. 164-172

Rosengren, A., Hawken, S., Ounpuu, S., Sliwa, K., Zubaid, M., Almaheed, W.A., Blackett, K.N.,SitthiAmorn, C., Sato, H., and Yusuf, S. (2004), “Association of psychological risk factors with $n$ Risk of acute myocardial infarction in 11,119 cases and 13,648 controls from 52 countries (the INTERHEART Study): A Case-Control Study", Lancet, Vol. 364 No. 9438, pp. 953-962

Schaufeli, W.B., and Bakker, A.B. (2004), "Job demands, job resources, and their relationship with burnout and engagement: a multi-sample study", Journal of Organizational Behaviour, Vol. 25, pp. 293-315

Schaufeli, W.B., Bakker, A.B., and Van Rhenan, W. (2009), "How changes in job demands and resources predict burnout, work engagement, and sickness absenteeism", Journal of Organizational Behaviour, Vol. 30, pp. 893-917

Seligman, M.E.P., and Csikzentmihalyi, M. (2000), "Positive Psychology: An Introduction", American Psychologist, Vol. 55 No. 1, pp. 5-14

Seymour, .L., and Grove, B. (2005), "Workplace interventions for people with common mental health problems: Evidence review and recommendations", British Occupational Health Research Foundation, London. Available: http://www.bohrf.org.uk/downloads/cmh rev.pdf (accessed 20th April 2017)

Steyne, T. (2009), "Inviting schools in the United States of America and Hong Kong: An Appreciative Inquiry", Journal of Invitational Theory and Practice, Vol. 15, pp. 4-18

Van den Tooren, M., and De Jonge, J. (2008), "Managing job stress in nursing: what kind of resources do we need?" Journal of Advanced Nursing, Vol. 63 No. 1, pp. 75-84.

Van Wyck, B.E., and Pillay-Van Wyck, V. (2010), "Preventative staff-support interventions for health workers", Cochrane Database of Systematic Reviews, Vol. 3, Article no. CD003541

Yusuf, S., Hawken, S., Onpuu, S., Dans,T., Avezum, A., Lanas, F., McQueen, M., Budaj, A., Pais, P., Varigos, J., and Lisheng, L. (2004), "Effect of potentially modifiable risk factors associated with myocardial infarction in 52 countries (the INTERHEART study): A Case-Control Study", Lancet, Vol. 364 No. 9438, pp. 937-952. 
Figure 2: Diagram summarising a local stress theory for the participating department.

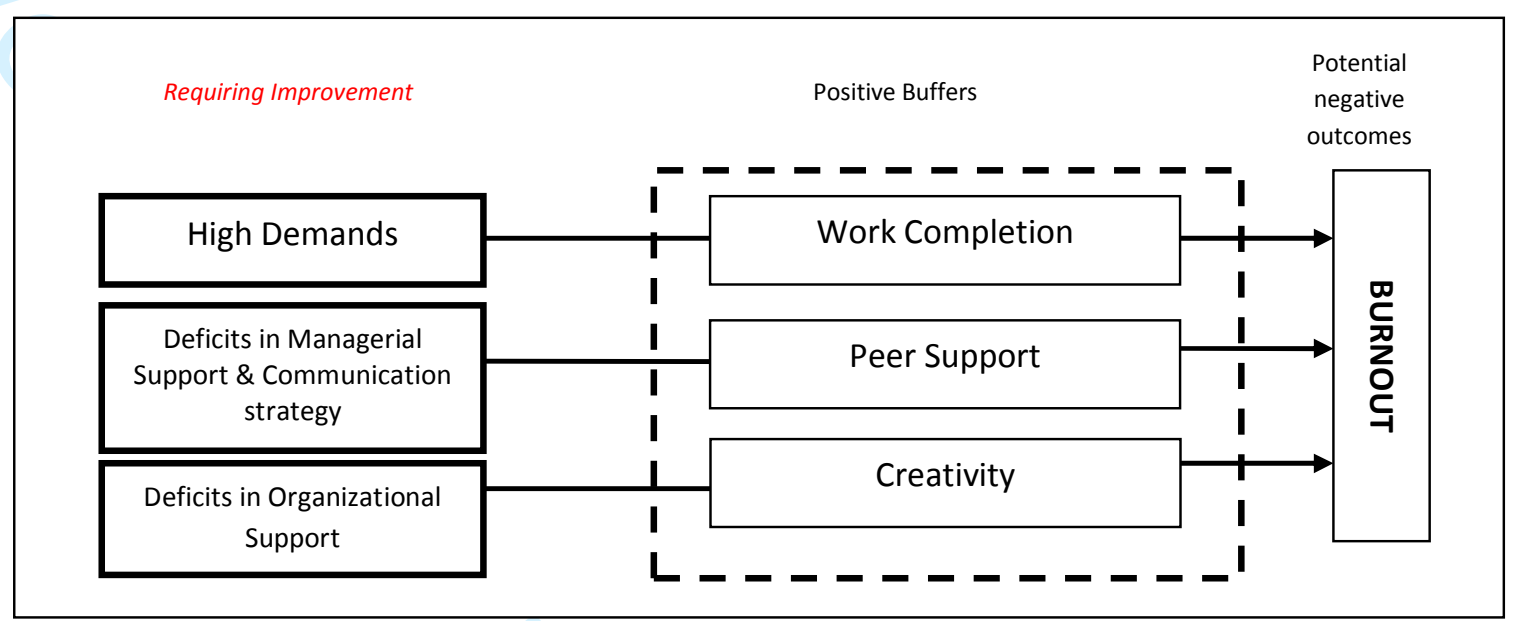

